\title{
RECOGNITION AND PRACTICE OF HOME-MANAGEMENT OF MALARIA AMONG MOTHERS OF UNDER-FIVE CHILDREN IN OBAFEMI OWODE COMMUNITY, ABEOKUTA, OGUN STATE
}

\author{
Aruoture Ochukooghene Anita ${ }^{1}$ and Ademola Amosu ${ }^{2}$ \\ ${ }^{1}$ Student, Department of Public Health and Allied Health Babcock, University, Ilishan-Remo, \\ Ogun State \\ ${ }^{2}$ Department of Public Health and Allied Health Babcock, University, Ilishan-Remo, Ogun \\ State.
}

Cite this article:

Aruoture O.A., Ademola A. (2021), Recognition and Practice of Home-

Management of Malaria among Mothers of UnderFive Children in Obafemi Owode Community, Abeokuta, Ogun State. African Journal of Health, Nursing and Midwifery 4(3), 105-120. DOI: 10.52589/AJHNMUR8BA0FI.

\section{Manuscript History}

Received: 10 May 2021

Accepted: 6 June 2021

Published: 20 June 2021

Copyright $\odot 2020$ The Author(s). This is an Open Access article distributed under the terms of Creative Commons Attribution-NonCommercialNoDerivatives 4.0 International (CC BY-NC-ND 4.0), which permits anyone to share, use, reproduce and redistribute in any medium, provided the original author and source are credited.
ABSTRACT: The study investigates the factors influencing the recognition and practice of Home-management of malaria among mothers of under-five children in Obafemi Owode Community, Abeokuta, Ogun State. The study employed a descriptive crosssectional design. The study employed a multi-staged sampling technique to select 299 nursing mothers of under-five children at the primary health care centre of Obafemi Owode Community. The main instrument for the study was a questionnaire. The selected sociodemographic variables were analyzed using the descriptive analysis while the hypotheses were tested using Pearson Product Moment Correlation and linear regression analysis. The result indicated that $38.5 \%$ of the nursing mothers had a high level of knowledge of homebased management of malaria. 55.9\% of the respondents had an average attitude towards home-based management of Malaria. $46.8 \%$ had a good level of practice of home-based management of malaria. There was a significant relationship between the demographic factors of nursing mothers and knowledge of home-based management of malaria among nursing mothers of Obafemi Owode Community, Abeokuta, Ogun State ( $p<.05)$. However, the age of mother is not significantly associated with knowledge of home-based management ( $p>0.05)$. The calculated $R$ Squared and $p$-value for demographic variables on practice of home-management of malaria among nursing mothers is: 0.788 which signifies $78.8 \%$ contribution to practice of home-management among nursing mothers. Hence, all demographic characteristics of nursing mothers are significant predictors of practice of home-based management of Malaria among Nursing mothers of Obafemi Owode Community, Abeokuta, Ogun State. The study recommended that Primary Health centres should put in place mechanisms for example incorporating components of home visit in the performance appraisal of community Health Officers to ensure the recommended number of visits are adhered to. Also, caregivers' seemingly inability to correctly dissociate between the two essentials of knowledge related to malaria can be addressed by Community Health Officers through the home visit programme.

KEYWORDS: Home-Management, Malaria Mothers, Primary Health Centres, Children, Ogun State, Nigeria 


\section{INTRODUCTION}

\section{Background}

Malaria is still a major global health problem and one of the leading causes of mortality and morbidity in sub-Saharan Africa. In 2010, an estimated 216 million cases and 655,000 deaths of malaria occurred worldwide, of which about $81 \%$ and $91 \%$ respectively were in the African Region. Most of the cases and deaths were reported in $<5$ year children (WHO, 2019). Ninety percent of these deaths occur in Sub-Saharan Africa and 70\% are of children under the age of 5 years. This is equivalent to one child in Africa dying of malaria every 30 seconds (Against Malaria Foundation, 2013).

Report from the World Malaria study indicated that there were 216 million cases of malaria and more than 445,000 deaths due to the disease in 2019 (WHO, 2019) The disease is severe in the endemic areas of sub-Saharan Africa, which accounts for $90 \%$ of global malaria deaths (2019). The poor health status of the region's population and limited access to health-care services exacerbate vulnerability to the disease. Nigeria has one of the highest rates of the transmission of malaria with more than $76 \%$ of the population reporting more than 1 case per 1,000 populations. Malaria has also been shown to be responsible for high school absenteeism, neurodisability and impairment of cognitive development in children (Jegede, 2019; Ajayi, 2019). It is estimated that $92 \%$ of these deaths occur at home; hence, mothers and caregivers are of foremost importance in recognizing mild or severe malaria disease and seeking treatment for their wards. Most caregivers begin treatment at home with antimalarial drugs and antipyretics bought from patent medicine stores (Okeke, 2019; Goodman, 2018), without a prescription and usually administered in inappropriate doses (WHO, 2019).

Thus, less than $15 \%$ of the malaria episodes treated at home are treated incorrectly, leading to the increasing child mortality across rural communities in Nigeria. Home-based management of malaria could improve prompt access to antimalarial medications for African children as documented by several studies which have investigated home based management practices of malaria caregivers in children below five years and beyond in various parts of Nigeria and beyond (Ajayi, 2019; Chukwuocha, 2019; Adeneye, 2018; Kassam, 2019; Ahorlu, 2016; Kamat, 2018). Although these studies made significant observations as to the knowledge level of these care-givers, their preferred source of drugs and their drug treatment practices, there still exists gaps as to the home management practices in Nigeria. Similarly, Adebayo, (2019) reports poor knowledge of malaria vectors among nursing mothers in Kaduna State. These mothers attribute severe malaria, involving convulsion, to evil spirits. The study shows how these perceptions foster reliance on local healing practices and traditional healers over biomedical treatment. Among the Bwatiye people of northeastern Nigeria, Akogun and John, (2019) reported that malaria is ignored for the first 2 days. Active treatment seeking commences if the illness persists and intensifies.

Similarly, Ajala and Wilson, (2019) explore how local etiological beliefs, which attribute malaria to witchcraft, sunlight, and consumption of yellowish food items, encourage homebased management and interfere with utilization of modern healthcare services among the Ibibio people of south-coastal Nigeria. Additionally, over $40 \%$ of cases presented among under-five children in Obafemi Owode Primary Health Centre are related to malaria and other sepsis. Moreover, nursing mothers complain of non-availability of malaria preventive kits like ITN and high cost of anti-malaria drugs. Therefore, the thrust of this study is to examine the 
cognitive factors influencing the recognition and practice of Home-management of malaria among mothers of under five children in Obafemi Owode Community, Abeokuta, Ogun State.

\section{Research Questions}

1. What are the level of knowledge of home-based management of Malaria among Nursing mothers of Obafemi Owode Community

2. What is the level of practice of home-based management of Malaria among Nursing mothers of Obafemi Owode Community

\section{Objective of the study}

The main objective of this study is to investigate the cognitive factors influencing the recognition and practice of home-management of malaria among mothers of under-five children in Obafemi Owode Community, Abeokuta, Ogun State.

\section{Specific Objectives}

1. To determine the level of practice of home-based management of Malaria among nursing mothers of Obafemi Owode Community

2. To determine the relationship between demographic characteristics(age, occupation, religion and level of education) of nursing mothers and practice of home-based management of Malaria among Nursing mothers of Obafemi Owode Community, Abeokuta, Ogun State

\section{Research Hypotheses}

The following research hypotheses were tested for the study;

H0: Demographic characteristics of nursing mothers is a predictor of practice of home-based management of Malaria among Nursing mothers of Obafemi Owode Community, Abeokuta, Ogun State.

\section{Methods and Designs}

The study used a descriptive cross-sectional design. This design was considered more appropriate than other methods of research design because it assists in obtaining information about the cognitive factors influencing the recognition and practice of Home-management of malaria among mothers of under five children in Obafemi Owode Community, Abeokuta, Ogun State. This method was also considered than other methods of research design because it answers the research question and enquiry of interest to the researcher and it provides information about phenomena or relationships among phenomena at a fixed point in time (Adejare, 2019).

\section{Description of study Area}

The study area was conducted among Obafemi Owode is a Local Government Area in Ogun State, Nigeria. Its headquarters are in the town of Owode at $6^{\circ} 57^{\prime} \mathrm{N} 3^{\circ} 30^{\prime} \mathrm{E}$. It has an area of $1,410 \mathrm{~km}^{2}$ and a population of 228,851 at the 2006 census. Obafemi Owode Local Government is one of the Local Governments that came into existence through Edict No.9 of 1976, resulting 
from the 1976 Local Government reforms, prior to this period, the administration of the area was carried out by Oba Provincial Authority, Owode District Council and Obafemi District Council. Obafemi Owode Local Government is made up of people residing in Adigbe, Oba, Kobape, Obafemi, Ogunmakin, Ajebo, Owode, Mowe, Ibafo, Iro town and Mokoloko towns and they are mostly Egbas. Therefore, the common language being spoken is Yoruba with the Egba dialect. The traditional institution of the people is predominantly governed by Baales with the exception of a very early settlement called Iro, Oba Sanusi Ogunrinde Oyero. Eribi IV. An insight into the cultural aspects of the people reveals that they are blessed with rich Yoruba traditional dances such as Ogodo dance, Egungun and Bolojo dances, in some areas of the Local Government.

\section{Population}

Obafemi Owode Local Government has a Primary Healthcare Centre with competent staff and facilities. In all, there are 4 medical doctors and 46 para-medical staffers while there are 22 health clinics and 12 health posts. Both human and material resources are evenly spread all over the health districts. Recently commissioned, are two newly completed health clinics to boost the health projection plan of the Local Government. The primary health centre has postnatal care centre where nursing mothers of under-five children attend the clinic. The total of 318 mothers attends the post-natal clinic of the Obafemi Owode Primary Health Care centre on a monthly basis.

Inclusion criteria: All consenting and registered nursing mothers attending the post-natal primary health care clinic of the Obafemi Owode LGA. All nursing mothers must be above the age of 18years.

Exclusion criteria: All non-consenting nursing mothers and male respondents were excluded from the study. Also, individuals not registered for the primary health care centre were excluded from the study.

\section{Sample Size and Sample Technique}

Sample size is estimated using the Kish Leslie (1965) formula for quantitative studies. This was calculated based on a similar local study done in Oyo State which reported 23\% compliance with malaria prevention among nursing mothers in Ibadan (Bello \& Ayede, 2019).

$\mathrm{N}=\underline{\mathrm{Z}^{2}} \underline{\underline{P}} \underline{\mathrm{P}(1-\mathrm{P})}$

$\mathrm{D}^{2}$

\section{Where,}

$$
\begin{array}{ll}
\mathrm{N} & =\text { minimum sample size } \\
\mathrm{P} & =\text { the estimated prevalence of value, } 23 \% \text { in this study. } \\
\mathrm{D} & =\text { the absolute precision of the study which is } 0.05 \\
\mathrm{Z} & =\text { area under normal curve corresponding to } 95 \% \text { confidence interval. } \\
& =1.96
\end{array}
$$




Therefore,
$\mathrm{N} \quad=\quad \frac{(1.96)^{2}}{\mathrm{~N}} \frac{\mathrm{x} 0.23 \times(1-0.23)}{0.05^{2}}$
$\mathrm{~N} \quad=\frac{3.8416 \times 0.23 \times 0.77}{0.0025}$
$\mathrm{~N} \quad=\frac{3.8416 \times 0.1771}{0.0025}$
$\mathrm{~N} \quad=\quad \underline{0.6804}$
$\mathrm{~N} \quad=\quad 272$

$10 \%$ addition to the attrition rate indicated that $272+27.2=299$ nursing mothers were selected for the study at the Obafemi Owode Primary Health care centre, Abeokuta.

\section{Sampling Size}

The sample size is 299 nursing mothers in Obafemi Owode Primary Health care centre, Abeokuta. $10 \%$ addition to the attrition rate indicated that $272+27.2=299$ nursing mothers were selected for the study at the Obafemi Owode Primary Health care centre, Abeokuta.

\section{Sampling Technique}

The study employed a simple random sampling technique to select 299 nursing mothers attending the Obafemi Owode Primary Health care centre, Abeokuta. The researcher used balloting to select the nursing mother attending the PHC over a period of 2 weeks.

\section{Instrument for Data Collection}

The researcher developed self-administered 52 item questionnaires focusing on cognitive factors and practice of home-base management of malaria among nursing mothers. The questionnaires were divided into four (4) sections, they include; socio-demographics characteristics, knowledge of Malaria among nursing mothers and practice of home management of malaria among nursing mothers. The sections are presented below:

Section A: Demographic Characteristics: This includes socio-demographic characteristics which are age, marital status, education level, occupation, religion and ethnicity of nursing mothers in Obafemi Owode Primary Healthcare Centre, Abeokuta.

Section B: Cognitive factors of Malaria: These were item questions focusing on the general knowledge measured using Yes or No responses while attitude and perception of nursing mothers towards malaria among under-five children were measured using a four (4) Likert scale format (Strongly-Agree, Agree, Strongly-Disagree, Disagree). 
Section C: Practice of Home management of Malaria: This section focused on questions of practice of home-management of malaria. This section consisted of 10 item questions on different practices of home-management of Malaria. Respondents were asked to respond questions relating to home-based management of malaria in under-five children

\section{Validity and Reliability of Instrument}

Validity: The face validity of the questionnaire was established by the supervisor.

Construct validity: This is the conceptual model to access the variables for the study. The content validity of the instrument was used to examine the internal consistency of the instrument by an external person from another department.

Reliability: Reliability analysis was done to determine the consistency level of the research instrument and this was done through a test-retest. After this, a pilot study was done to ensure that the questions are easy to understand and not ambiguous and also to learn how long it was taken for the respondents to complete the survey. Cronbach Alpha was used to test the reliability of the instrument.

\section{Reliability Table}

\begin{tabular}{|l|l|l|}
\hline Variable & Cronbach Alpha & Number Of Items \\
\hline Knowledge of malaria & .806 & 9 \\
\hline Practice of home-management malaria & .714 & 8 \\
\hline factors & .881 & 10 \\
\hline
\end{tabular}

\section{Method of Data Collection}

Data was collected during the post-natal clinic of nursing mothers of Obafemi Owode Primary Health care centre, Abeokuta. Approval to conduct the study was obtained from the Director of Medical Services of Obafemi Owode Primary Health care centre. The participants were served the questionnaire constructed in English language and there was a translation in Yoruba language. The questionnaire was self-administered with guidance from trained assistants. Correctly-filled questionnaires were returned to the researcher immediately and they were verified for accuracy.

\section{Method of Data Analysis}

Data entry was done using SPSS statistical package version 27, followed by cleaning, coding, and editing. Data was cleaned before being used in order to remove apparent errors. Frequency tables for all questions were used to identify missing information, detecting entry errors, and checking for inconsistencies such as outliers. The statistical analysis was done through descriptive and inferential analysis (Pearson Product Moment Correlation and Regression Analysis). The selected socio-demographic variables were analysed using the descriptive analysis. Frequency distribution, percentages, standard deviation, and mean score was calculated and presented in the form of tables. 


\section{Ethical Consideration}

The research commenced after ethical approval was granted from Babcock University-Health Research Ethics Committee (BUHREC). At each of the selected study site, members of the community development association were contacted for consent and relevant data before the commencement of the study. Informed consent was also sought from the participants before the administration of the questionnaire. Data is kept as confidential as possible.

\section{RESULTS}

Table 1 Analysis of Characteristics of the nursing mothers $\mathrm{N}=299$

\begin{tabular}{|c|c|c|}
\hline Characteristics of nursing mothers & Frequency & Percentage \\
\hline \multicolumn{3}{|l|}{ Religion } \\
\hline Christianity & 208 & 69.6 \\
\hline Islam & 91 & 30.4 \\
\hline \multicolumn{3}{|l|}{ Age of mother } \\
\hline 21-25years & 111 & 37.1 \\
\hline 26-30years & 49 & 16.4 \\
\hline 31-35years & 47 & 15.7 \\
\hline 36 years and above & 92 & 30.8 \\
\hline \multicolumn{3}{|l|}{ Mean Age of Mother $=35.1 \pm 7.72$} \\
\hline \multicolumn{3}{|l|}{ Marital Status of Mother } \\
\hline Never married & 54 & 18.1 \\
\hline Married & 209 & 69.9 \\
\hline Separated & 19 & 6.4 \\
\hline others & 17 & 5.7 \\
\hline \multicolumn{3}{|l|}{ Tribe of the family } \\
\hline Yoruba & 251 & 83.9 \\
\hline Igbo & 16 & 5.4 \\
\hline Hausa & 16 & 5.4 \\
\hline Others & 16 & 5.4 \\
\hline \multicolumn{3}{|l|}{ Age of the Child } \\
\hline Less than 5months & 32 & 10.7 \\
\hline 6months-1year & 144 & 48.2 \\
\hline $1-5$ years & 123 & 41.1 \\
\hline \multicolumn{3}{|l|}{ Gender of the Child } \\
\hline Male & 154 & 51.5 \\
\hline Female & 145 & 48.5 \\
\hline \multicolumn{3}{|l|}{ Occupation of mother } \\
\hline Unemployed & 50 & 16.7 \\
\hline Trading & 35 & 11.7 \\
\hline Schooling & 127 & 42.5 \\
\hline Civil servant & 71 & 23.7 \\
\hline Other & 16 & 5.4 \\
\hline
\end{tabular}




\section{Level of Education}

No formal education

Primary school education

Secondary school education

Tertiary education

Table 1 presented above indicated that majority of the women, $69.6 \%$ are Christian by faith, $30.4 \%$ are Muslim. 37.1\% of the nursing mothers are between the ages of 21-25years, 30.8\% are above the age of 36years, $16.4 \%$ are between the ages of $26-30 y e a r s$, while $15.7 \%$ are between the ages of 31-35years. $69.9 \%$ of the mothers are married, $18.1 \%$ are never married, $6.4 \%$ are separated while $5.7 \%$ represent other marital status. $83.9 \%$ of the respondents are predominantly from the Yoruba tribe. 5.4\% are for Igbo, Hausa, and other tribes. $48.2 \%$ of the children are between the ages of 6month to 1 year, $41.1 \%$ are between the ages of $1-5 y e a r s$, while $10.7 \%$ are less than 5months. $48.5 \%$ of the children are female while $51.5 \%$ of the children are Male. $42.5 \%$ of the nursing mothers are schooling, $23.7 \%$ are civil servants, $16.7 \%$ are unemployed, $11.7 \%$ are traders while $5.4 \%$ represent other occupation. $42.5 \%$ of the nursing mothers had secondary school education, $23.7 \%$ had no formal education, $23.1 \%$ had primary school education while $10.7 \%$ had tertiary level of education.

Table 2 Analysis of Knowledge of Home-Based Management of Malaria $\mathrm{N}=299$

\begin{tabular}{lcc}
\hline Knowledge of Home-Based Management of Malaria & Frequency & Percentage \\
\hline Have you heard about malaria? & 210 & 70.2 \\
Yes & 89 & 29.8 \\
No & 32 & 10.7 \\
Where did you hear about malaria? & 88 & 29.4 \\
Hospital & 90 & 30.1 \\
Radio/Television & 55 & 18.4 \\
I suffered from it & 34 & 11.4 \\
Friend and family & & \\
Other sources & & \\
What are the major signs of malaria in under-five & 34 & 11.4 \\
children? & 104 & 34.8 \\
Headaches & 107 & 35.8 \\
Fever & 54 & 18.1 \\
loss of appetite & & \\
convulsion & & \\
What are the major causes of malaria in under-five & 35 & 11.7 \\
children? & 73 & 24.4 \\
Germs & 19 & 6.4 \\
Plasmodiumparasite & 52 & 17.4 \\
bushy environment & 17 & 5.7 \\
Weakness & 33 & 11.0 \\
Bite of infective female anopheles mosquito & & \\
Dirt/Stagnant water & & \\
& &
\end{tabular}


Weakness

I do not know

When your child has malaria what do you do?

Take child to the hospital

Not give any medication and takes the child to the clinic for the treatment

Takes the child to the herbalist for treatment

Give anti-malaria drugs

Others

What do you do to prevent mosquitoes from biting a under-five child?

Cleaning the surrounding

Sleeping under treated net

Giving medication regularly

Others
51

19

55

119

55

51

19

70

125

68

36
17.1

6.4

18.4

39.8

18.4

17.1

6.4

23.4

41.8

22.7

12.0

Table 2 presented above showed that $70.2 \%$ of the nursing mothers have heard about malaria, $29.8 \%$ have not heard about malaria. $30.1 \%$ of the nursing mothers are reported to have heard about malaria because they have suffered from it, $29.4 \%$ reported to have heard about it on the radio/ television, $18.4 \%$ reported to have heard about it from friend and family, $11.4 \%$ reported to have heard about it from other sources while $10.7 \%$ reported to have heard about it from the hospital since the hospital happens to be the main source of information about Malaria. 35.8\% of the mothers reported loss of appetite, $34.8 \%$ reported fever, $18.1 \%$ reported convulsion, while $11.4 \%$ reported headaches. $24.4 \%$ of the respondents reported Plasmodium Parasite, $17.4 \%$ reported weakness as one of the signs, $17.1 \%$ reported loss of energy, $11.7 \%$ reported germs as one of the major causes, $11 \%$ reported dirt/stagnant water, $6.4 \%$ reported bushy environment while 5.7\% reported bite of ineffective female anopheles mosquito. $39.8 \%$ of the nursing mothers often take their children to the clinic for appropriate treatment, $18.4 \%$ reported that they take their children to the hospital and also take their children to the herbalist for treatment. $17.1 \%$ reported that they give their children anti-malaria drugs, while $6.4 \%$ reported deploying other methods of treatment. $41.8 \%$ reported sleeping under the treated net as a major preventive method of malaria for under-five children. $23.4 \%$ reported cleaning the surrounding, $22.7 \%$ reported giving medication regularly while $12 \%$ reported other means.

\section{Answering of research questions one on the level of knowledge of Home-Based Management of Malaria}

Table 2b: Summary of level of knowledge of Home-Based Management of Malaria $\mathrm{N}=299$

\begin{tabular}{ccc}
\hline Criteria & Frequency & Percentage \\
\hline High (15-22) & 115 & 38.5 \\
Average (8-14) & 77 & 25.8 \\
Low(1-7) & 107 & 35.8 \\
& Mean $=\mathbf{1 6 . 8}$, Std. Dev $=\mathbf{2 . 9 8}$ & \\
\hline
\end{tabular}


This study asked 6 questions relating to the level of knowledge of home-based management of Malaria. Maximum score obtainable is 22. Their knowledge is categorized as High (15-22), Average (8-14) and low (1-7). 38.5\% of the nursing mothers had a high level of knowledge of home-based management of malaria, $35.8 \%$ had a low level of knowledge of home-based management of malaria while $25.8 \%$ had average knowledge of home-based management of malaria.

Table 3 Analysis of Home-Management Practice of Malaria

$\mathbf{N}=\mathbf{2 9 9}$

\begin{tabular}{|c|c|c|}
\hline Home-Management Practice of Malaria & Frequency & Percentage \\
\hline \multicolumn{3}{|l|}{ Do you practice home management of malaria? } \\
\hline Yes & 212 & 70.9 \\
\hline No & 87 & 29.1 \\
\hline \multicolumn{3}{|c|}{ How often do you practice home-management of malaria? } \\
\hline Frequently & 120 & 40.1 \\
\hline Occasionally & 16 & 5.4 \\
\hline Not too often & 90 & 30.1 \\
\hline not at all & 73 & 24.4 \\
\hline \multicolumn{3}{|l|}{ What is the most preferred malaria therapy? } \\
\hline Antimalaria monotherapy & 122 & 40.8 \\
\hline Artemether-Lumefantrine Combination therapy & 141 & 47.2 \\
\hline Others & 36 & 12.0 \\
\hline \multicolumn{3}{|l|}{ Most preferred drug utilized } \\
\hline Chloroquine & 108 & 36.1 \\
\hline Fansidar & 109 & 36.5 \\
\hline Quinine & 66 & 22.1 \\
\hline Artemether-Lumefantrine Combination therapy & 16 & 5.4 \\
\hline \multicolumn{3}{|l|}{ Source of drug used for therapy } \\
\hline Friends & 35 & 11.7 \\
\hline Pharmacy & 106 & 35.5 \\
\hline Drug sellers such chemist & 104 & 34.8 \\
\hline Left over from previous hospital & 54 & 18.1 \\
\hline \multicolumn{3}{|l|}{ Reasons for home based treatment } \\
\hline No money & 53 & 17.7 \\
\hline High cost of treatment & 125 & 41.8 \\
\hline distance of health of facility & 121 & 40.5 \\
\hline \multicolumn{3}{|l|}{ Preventive Practice } \\
\hline mosquito nets & 35 & 11.7 \\
\hline maintain clean surroundings & 74 & 24.7 \\
\hline take herbs & 138 & 46.2 \\
\hline Indoor spray & 52 & 17.4 \\
\hline \multicolumn{3}{|c|}{$\begin{array}{l}\text { First treatment given to the child when you noticed } \\
\text { malaria }\end{array}$} \\
\hline Gave herbs at home & 35 & 11.7 \\
\hline child taken to traditional medicine & 54 & 18.1 \\
\hline gave orthodo drugs at home & 105 & 35.1 \\
\hline
\end{tabular}


Mention the name of $\operatorname{drug}(\mathrm{s})$ bought from the chemist/PMS or drug hawker for home treatment of malaria

Chloroquine

Aspirin

Antibiotics

Piriton

Blood tonic

What was the outcome of the treatment you gave your child at home?

Got well

Got a little better

There was no improvement in child's condition

Table 3 presented above indicated that $70.9 \%$ of the mothers reported to practice homemanagement of malaria. $40.1 \%$ frequently practice home-management of malaria, $30.1 \%$ not too often, $24.4 \%$ reported not at all, $5.4 \%$ reported to practice home management occasionally. $40.8 \%$ of the nursing mothers preferred to use Anti Malaria monotherapy as malaria therapy, $47.8 \%$ reported the use of Arthemether-Lumefantrine Combination therapy, $12 \%$ reported the use of other malaria therapy. $36.5 \%$ reported the use of fansidar, $36.1 \%$ reported the use of chloroquine, $22.1 \%$ reported the use of Quinine, 5.4\% reported the use of ArthemetherLumefantrine Combination therapy. $35.5 \%$ of the respondents got their drugs from the Pharmacy, $34.8 \%$ reported from the drug sellers like the chemist, $18.1 \%$ reported to use the left over from the previous hospital, $11.7 \%$ reported to have contacted their friends.

$41.8 \%$ of the mothers reported the high cost of treatment, $40.5 \%$ reported the use of distance of health of the facility while $17.7 \%$ reported lack of money. $46.2 \%$ of the nursing mothers reported taking herbs as preventive practice of malaria, $24.7 \%$ reported maintaining clean surroundings, $17.4 \%$ reported indoor spraying while $11.7 \%$ reported the use of mosquito nets. $35.1 \%$ of the respondents reported to give their children orthodox drug in their home, $22.7 \%$ reported that they took their children to chemist/PMS, $18.1 \%$ reported taking their children to a traditional medicine while $12.4 \%$ reported to take their children to a health care centre for treatment while $11.7 \%$ reported giving their children herbs at home. Most of the women mentioned the names of the drugs that were given to the children, $47.8 \%$ mentioned the use of paracetamol, 12\% mentioned Aspirin, 12\% mentioned antibiotics, 11\% mentioned piriton, 6.4\% mentioned Chloroquine while 5.4\% mentioned blood tonic and other medications. In terms of the outcome of treatment, $39.7 \%$ reported to get well, $35.8 \%$ reported that they got little better, $18.1 \%$ reported sickness later got worse while $6.4 \%$ reported that there was no improvement on their children's condition. 
Answering of research questions three on the level of practice of Home-Based Management of Malaria

Table 3b: Summary of level of practice of Home-Based Management of Malaria N=299

\begin{tabular}{ccc}
\hline Criteria & Frequency & Percentage \\
\hline Good (20-29) & 140 & 46.8 \\
Average (10-19) & 71 & 23.7 \\
Poor(1-9) & 88 & 29.4 \\
& Mean $=\mathbf{2 4 . 4}$, Std. Dev $=\mathbf{3 . 9 7}$ & \\
\hline
\end{tabular}

This study asked 10 questions on the level of practice of home-based management of Malaria. Maximum score obtainable is 29. Their preparedness is categorized as Good (20-29), Average (10-19) and Poor (1-9). 46.8\% have a good level of practice of home-based management of malaria, 29.4\% have poor level of practice of home-based management of malaria, while $23.7 \%$ had average level of practice of home-based management.

\section{Research Hypotheses}

Hypothesis One: There is a significant relationship between demographic characteristics of nursing mothers and knowledge of home-based management of Malaria among Nursing mothers of Obafemi Owode Community, Abeokuta, Ogun State

Table 4: Cross Tabulation showing correlation between demographic characteristics of nursing mothers and knowledge of home-based management of Malaria among Nursing mothers of Obafemi Owode Community, Abeokuta, Ogun State

\begin{tabular}{|c|c|c|c|c|c|}
\hline \multirow[t]{2}{*}{$\begin{array}{l}\text { Demographic characteristics } \\
\text { of nursing mothers }\end{array}$} & \multicolumn{3}{|c|}{$\begin{array}{c}\text { Knowledge of Home based } \\
\text { management malaria }\end{array}$} & \multirow[t]{2}{*}{ Total } & \multirow[t]{2}{*}{$\begin{array}{c}\mathbf{R} \\
\text { p-value }\end{array}$} \\
\hline & Good & Fair & Poor & & \\
\hline \multicolumn{6}{|l|}{ Age of mother } \\
\hline \multirow[t]{2}{*}{$21-25$ years } & 44 & 27 & 40 & 111 & \multirow{8}{*}{$\begin{array}{r}0.771 \\
0.13\end{array}$} \\
\hline & $38.3 \%$ & $35.1 \%$ & $37.4 \%$ & $37.1 \%$ & \\
\hline \multirow[t]{2}{*}{ 26-30years } & 20 & 12 & 17 & 49 & \\
\hline & $17.4 \%$ & $15.6 \%$ & $15.9 \%$ & $16.4 \%$ & \\
\hline \multirow[t]{2}{*}{ 31-35years } & 16 & 12 & 19 & 47 & \\
\hline & $13.9 \%$ & $15.6 \%$ & $17.8 \%$ & $15.7 \%$ & \\
\hline \multirow[t]{2}{*}{36 years and above } & 35 & 26 & 31 & 92 & \\
\hline & $30.4 \%$ & $33.8 \%$ & $29.0 \%$ & $30.8 \%$ & \\
\hline \multicolumn{6}{|l|}{ Occupation of mothers } \\
\hline \multirow[t]{2}{*}{ Unemployed } & 22 & 12 & 16 & 50 & \multirow{8}{*}{$\begin{array}{r}0.841 \\
0.000^{* *}\end{array}$} \\
\hline & $19.1 \%$ & $15.6 \%$ & $15.0 \%$ & $16.7 \%$ & \\
\hline \multirow[t]{2}{*}{ Trading } & 13 & 9 & 13 & 35 & \\
\hline & $11.3 \%$ & $11.7 \%$ & $12.1 \%$ & $11.7 \%$ & \\
\hline \multirow[t]{2}{*}{ Schooling } & 48 & 31 & 48 & 127 & \\
\hline & $41.7 \%$ & $40.3 \%$ & $44.9 \%$ & $42.5 \%$ & \\
\hline \multirow[t]{2}{*}{ Civil servant } & 24 & 22 & 25 & 71 & \\
\hline & $20.9 \%$ & $28.6 \%$ & $23.4 \%$ & $23.7 \%$ & \\
\hline
\end{tabular}




\begin{tabular}{|c|c|c|c|c|c|}
\hline Other & 8 & 3 & 5 & 16 & \\
\hline & $7.0 \%$ & $3.9 \%$ & $4.7 \%$ & $5.4 \%$ & \\
\hline \multicolumn{6}{|l|}{ Religion } \\
\hline \multirow[t]{2}{*}{ Christianity } & 83 & 52 & 73 & 208 & \multirow{4}{*}{$\begin{array}{l}0.833 \\
0.011\end{array}$} \\
\hline & $72.2 \%$ & $67.5 \%$ & $68.2 \%$ & $69.6 \%$ & \\
\hline \multirow[t]{2}{*}{ Islam } & 32 & 25 & 34 & 91 & \\
\hline & $27.8 \%$ & $32.5 \%$ & $31.8 \%$ & $30.4 \%$ & \\
\hline \multicolumn{6}{|l|}{ Level of Education } \\
\hline \multirow[t]{2}{*}{ No formal education } & 25 & 12 & 34 & 71 & \multirow{8}{*}{$\begin{array}{r}0.671 \\
0.000^{* *}\end{array}$} \\
\hline & $21.7 \%$ & $15.6 \%$ & $31.8 \%$ & $23.7 \%$ & \\
\hline \multirow[t]{2}{*}{ Primary school } & 29 & 21 & 19 & 69 & \\
\hline & $25.2 \%$ & $27.3 \%$ & $17.8 \%$ & $23.1 \%$ & \\
\hline \multirow[t]{2}{*}{ Secondary school } & 45 & 38 & 44 & 127 & \\
\hline & $39.1 \%$ & $49.4 \%$ & $41.1 \%$ & $42.5 \%$ & \\
\hline \multirow[t]{2}{*}{ Tertiary education } & 16 & 6 & 10 & 32 & \\
\hline & $13.9 \%$ & $7.8 \%$ & $9.3 \%$ & $10.7 \%$ & \\
\hline
\end{tabular}

** significant at $<0.05$ level of significance

The result of hypothesis one indicated there was a significant relationship between the demographic characteristics of nursing mothers and knowledge of home-based management of Malaria among Nursing mothers of Obafemi Owode Community, Abeokuta, Ogun State $(\mathrm{p}<$ $.05)$. However, the age of mother is not significantly associated with knowledge of home-based management ( $p>0.05$ ). This implies that the null hypothesis is rejected while the alternate hypothesis is accepted. This accentuates that the demographic characteristics of nursing mothers correlate with the knowledge of home-based management of Malaria among Nursing mothers of Obafemi Owode Community, Abeokuta, Ogun State

Hypothesis two: Demographic characteristics of nursing mothers is a predictor of practice of home-based management of Malaria among Nursing mothers of Obafemi Owode Community, Abeokuta, Ogun State.

Table 5: Regression showing demographic characteristics as a predictor of practice of home-based management of Malaria among nursing mothers

$\mathrm{R}=0.661$
$\mathrm{R}^{2}=0.788$

Adjusted $\mathrm{R}^{2}=0.801$

Standard Error $=1.8221$

\begin{tabular}{|l|r|r|r|r|} 
& \multicolumn{1}{|c|}{ B } & Std. Error & t & \\
\hline (Constant) & 3.618 & .357 & 4.534 & .000 \\
\hline Religion & .133 & .117 & 1.279 & .000 \\
\hline Age of Mother & .108 & .308 & 0.112 & .000 \\
\hline Occupation of mother & .110 & .249 & 1.206 & \\
\hline Education of mother & .105 & .152 & 0.104 & .000 \\
\hline
\end{tabular}


The table (4.2.2) shows the regression square and p-value. Employing a 0.05 criterion of statistical significance, none of the variables had significant effects with the constant. The calculated R Squared and p-value for demographic variables on practice of home-management of malaria among nursing mothers is: 0.788 which signifies $78.8 \%$ contribution to practice of home-management among nursing mothers. Hence, all demographic characteristics of nursing mothers are a significant predictor of practice of home-based management of Malaria among Nursing mothers of Obafemi Owode Community, Abeokuta, Ogun State.

\section{DISCUSSION OF FINDINGS}

\section{Level of knowledge of home-based management of Malaria}

The result of research question one indicated that $38.5 \%$ of the nursing mothers had a high level of knowledge of home-based management of malaria, 35.8\% had a low level of knowledge of home-based management of malaria while $25.8 \%$ had an average knowledge of home-based management of malaria. The result corroborates with the findings of Moerman (2019) that the majority of women practicing home-management of malaria for the sake of their children had a good level of home treatment of malaria. The result is similar to that of McCombie (2019) that rural women residing in a resource-constrained environment have good understanding of home treatment of malaria because of the direct and especially indirect costs of seeking health care from formal facilities may be substantial, providing a major barrier for many households and low level of mother's education which has reduced the number of visits to clinics and hospitals. Furthermore, the result is in tandem with the findings of Fawole (2019) that mothers are primary caregivers and are usually the first to recognize signs of illness in their children. It has been demonstrated that educating mothers on malaria recognition and treatment can improve the effectiveness of malaria control programs

\section{Level of Practice of Home Management of Malaria}

The result of research question three indicated that $46.8 \%$ have a good level of practice of home-based management of malaria, $29.4 \%$ have poor level of practice of home-based management of malaria while $23.7 \%$ had average level of practice of home-based management. The result is in tandem with the findings of Agrawal (2019) that Treatment of malaria depends on the (presumptive) identification of the species of Plasmodium causing the infection, knowledge of the presence of resistant organisms in the area in which the malaria was contracted, national guidelines, antimalarial availability, individual patient factors and whether the malarial illness is categorized as either uncomplicated or severe. Furthermore, there is usually inappropriate treatment of malaria at home due to poor knowledge of causation and transmission of malaria as well as types and dosage of drugs used (Ajayi 2016, Falade, 2016). Hence, deterioration of initial uncomplicated malaria to complicated one leading to death of a very large number of the under-five children (Falade 2016, Orimadegun 2017). According to Orimadegun (2019), In Ibadan, South-west Nigeria observed that the risk of severe malaria in under-five children who received home-based treatment compared to those who did not but presented to the health facilities in acute disease was 1.63 and mortality was fourfold higher in the same group of children.

Hypothesis one: The result of hypothesis one showed that there was a significant relationship between the demographic characteristics of nursing mothers and knowledge of home-based 
management of Malaria among Nursing mothers of Obafemi Owode Community, Abeokuta, Ogun State $(p<.05)$. However, the age of mother is not significantly associated with knowledge of home-based management ( $p>0.05$ ). The result of the analysis is consistent with the findings Watsierah et al (2019) conducted in Western Kenya on anti-malarial use. They found that the anti-malarial drug use was related to age of the respondent, household size, household head, household source of income, monthly income, duration of use, dosage of drugs taken, and source of the drugs. Githinji et al (2019) conducted a study in rural areas of western Kenya on mosquito net ownership, use and quality. The study showed that children from poor households slept under nets with holes compared to the well-to-do households. In a similar study in Rajasthan, India, mothers from rich families utilise health facilities for treating fever in underfive children more than those from poor households (Yadav 2019). Additionally, the longer stay of mothers outside the room leads to bites of both mother and the under 5 years old. All research participants that had heard about malaria provided appropriate knowledge and attitudes about malaria by indicating that it can result in death if not managed. The participants gave wider sources of malaria information as well as their preference. Health facilities composed of the majority while community durbars were the second most preferred place of obtaining information on health. (Hlongwana, Mabaso, Kunene, Govender, \& Maharaj, 2019)

Hypothesis two: The result of hypothesis three showed that the demographic characteristics of nursing mothers are a significant predictor of practice of home-based management of Malaria among Nursing mothers of Obafemi Owode Community, Abeokuta, Ogun State. The result is consistent with that of Jinadu (2019) that in Benin City, the programme comprised training and re-training of healthcare providers, patent medicine vendors and role model caregivers at every level on current community case management of malaria while also focusing on their demographic characteristics. The result is consistent with that of Orimadegun (2019) in Ibadan, South-west Nigeria observed that the risk of severe malaria in under-five children who received home-based treatment compared to those who did not but presented to the health facilities in acute disease was 1.63 and mortality was fourfold higher in the same group of children. Additionally, Ebuehi (2018) opined that most fever occurring in children is first treated at home by mothers and caregivers and early recognition and correct management by mothers at home have been shown to impact outcome of the disease positively. However, there is usually an inappropriate treatment of malaria at home due to poor knowledge of causation and transmission of malaria as well as types and dosage of drugs used.

\section{CONCLUSION AND RECOMMENDATION}

Malaria has also been shown to be responsible for high school absenteeism, neurodisability and impairment of cognitive development in children. The Primary Health centres should put in place mechanisms. For example, incorporate components of home visit in the performance appraisal of community Health Officers to ensure the recommended number of visits are adhered to. This would ensure that the desired outcome of home visit is realized. Community Health Officers should emphasize on the differences between cause and transmission of malaria during home visit. Caregivers' seemingly inability to correctly dissociate between the two essentials of knowledge related to malaria can be addressed by Community Health Officers through the home visit programme. Home visit influence on LLIN utilization for children who did not sleep under the LLIN the previous night can be achieved by an increase in frequency of visits from the current once in a month to two times in a week. 


\section{REFERENCES}

Adebayo, A.C (2019) Initial evidence of reduction of malaria cases and deaths in Rwanda and Ethiopia due to rapid scale-up of malaria prevention and treatment. Malaria Journal. 14;8:14.

Adeneye, A. Y., (2018). Prevalence of malaria and anaemia during the dry season in North Central and South Western Nigeria. Journal of Parasitology and Vector Biology, 10(1), 8-18.

Against Malaria Foundation, (2013) Malaria in Africa, 2010; www.rbm.who.int accessed on $13 / 01 / 2013$.

Agrawal, S (2019)Genomic structure and diversity of Plasmodium falciparum in Southeast Asia reveal recent parasite migration patterns. Nature communications, 10(1), 1-11.

Ahorlu, C. K., (2016). Perceptions on the effect of small electric fans on comfort inside bed nets in southern Ghana: a qualitative study. Malaria journal, 15(1), 1-7.

Ajala, A.D., \& Wilson, O.O (2019). Ethnomedical Beliefs and Utilization of Alcohol Herbal Remedy for Malaria in South-Coastal Nigeria. International quarterly of community health education, 39(2), 119-126.

Ajayi, P.A (2019) Increases in correct administration of chloroquine in the home and referral of sick children to health facilities through a community-based intervention in Orolu LGA, Osun State. Trans R Soc Trop Med Hyg, 97:481-490.

Akogun, A.A., \& John, O.O., (2019) Home Management of Malaria: Knowledge, Attitude and Awareness of Mothers in Babcock University. American Journal of Biomedical and Life Sciences, 7(6), 133-142.

Chukwuocha, E.K (2019) Improving adherence to malaria treatment for children: the use of prepacked chloroquine tablets vs. chloroquine syrup. Trop Med Int Health, 6:496-504.

Fawole, I.F (2019) Determinants of intermittent preventive treatment of malaria among women attending antenatal clinics in primary health care centers in Ogbomoso, Oyo State, Nigeria. The Pan African Medical Journal, 33.

Goodman, K.O (2018) Impact of prepackaging antimalarial drugs on cost to patients and compliance with treatment. Bull World Health Organ, 79:394-399

Jegede, S (2019) Treatment of malaria outside the formal health services. J Trop Med Hyg, 98:29-34

Kamat, A., (2018). Comparative Malaria Diagnosis Using LH750 Beckman Coulter Automated Analyser in India: A Cross Sectional Case Control Study. Asian Hematology Research Journal, 1-8.

Kassam, R., (2019) Challenges with accessing health care for young children presumed to have malaria in the rural district of Butaleja, Uganda: a qualitative study. Pharmacy Practice (Granada), 17(4).

McCombie, Y.O (2019). Malaria morbidity, treatment-seeking behaviour, and mortality in a cohort of young children in rural Burkina Faso. Tropical Medicine \& International Health, 8(4), 290-296.

Moerman, G.O (2019) HIV-1 immune suppression and antimalarial treatment outcome in Zambian adults with uncomplicated malaria. The Journal of infectious diseases, 194(7), 917-925.

Okeke, C.O (2019) Treatment seeking for malaria: a review of recent research. Soc Sci Med, 43:933-945.

WHO, Nigeria, (2019) Malaria Prevalence in Nigeria. Abuja 